\title{
Thermodynamic and experimental investigations on the growth of thick aluminum nitride layers by high temperature CVD
}

\author{
A. Claudel ${ }^{\mathrm{a}, \mathrm{c}, *}$, E. Blanquet $^{\mathrm{a}}$, D. Chaussende ${ }^{\mathrm{b}}$, M. Audier $^{\mathrm{b}}$, D. Pique ${ }^{\mathrm{c}}$, M. Pons $^{\mathrm{a}}$ \\ a Science et Ingénierie des Matériaux et des Procédés, Grenoble INP-CNRS-UJF, BP 75, 38402 Saint Martin D'Hères, France \\ ${ }^{\mathrm{b}}$ Laboratoire des Matériaux et du Génie Physique, Grenoble INP-CNRS, 3 parvis Louis Néel, BP 257, 38016 Grenoble, France \\ ${ }^{c}$ ACERDE, 452 rue des sources, 38920 Crolles, France
}

\begin{abstract}
To achieve AlN bulk growth, high temperature CVD process using chlorine chemistry was investigated. High growth rate and high crystalline quality are targeted for both polycrystalline and epitaxial AlN films grown on $\left(\begin{array}{llll}0 & 0 & 0 & 1\end{array}\right) \alpha-\mathrm{Al}_{2} \mathrm{O}_{3}$ Sapphire and $\left(\begin{array}{llll}0 & 0 & 0 & 1\end{array}\right)$ off axis $4 \mathrm{H} \mathrm{SiC}$ or on axis $6 \mathrm{H} \mathrm{SiC} \mathrm{single} \mathrm{crystal}$ substrates. Thermodynamic calculations were carried out to select the more appropriate inert materials for the reactor and to understand the chemistries of Al chlorination and AlN deposition steps. The reactants were ammonia $\left(\mathrm{NH}_{3}\right)$ and aluminum chlorides $\left(\mathrm{AlCl} \mathrm{l}_{\chi}\right)$ species formed in situ using chlorine gas $\left(\mathrm{Cl}_{2}\right)$ reaction with high purity $\mathrm{Al}$ wires. Deposition temperature was varying from 1100 to $1800{ }^{\circ} \mathrm{C}$. Influences of temperature, total pressure, $\mathrm{Cl}_{2}$ flow rate and carrier gas $\left(\mathrm{Ar}\right.$ or $\mathrm{H}_{2}$ ) on growth rate, surface morphology and crystalline state are presented. As results, films morphology is related to a variation of the thermodynamic supersaturation. As-grown AlN layers surface morphologies were studied by SEM, FEG-SEM and AFM. Crystalline state, crystallographic orientations and epitaxial relationships with substrates were obtained from $\theta / 2 \theta$ X-ray diffraction and X-ray pole figure, respectively. Growth rates up to $200 \mu \mathrm{m} \mathrm{h}^{-1}$ have been reached for polycrystalline AlN layers.
\end{abstract}

\section{Introduction}

Aluminum nitride AlN is a wide bandgap III-V semiconductor material. AlN single crystal is expected to be a promising substrate material because of its wide direct bandgap $(\mathrm{Eg}=6.2 \mathrm{eV})$, its high electrical resistivity (between $10^{9}$ and $10^{13} \Omega \mathrm{cm}$ at $300 \mathrm{~K}$ ) and high thermal conductivity $\left(3.3 \mathrm{~W} \mathrm{~K}^{-1} \mathrm{~cm}^{-1}\right)$, its small difference in thermal expansion coefficient and small lattice mismatch with $\mathrm{SiC}$ and GaN. The availability of AlN single crystal substrates is expected for applications such as group III nitride optoelectronics blue and UV LEDs and LDs, high frequency and high power devices

\footnotetext{
${ }^{*}$ Corresponding author at: Science et Ingénierie des Matériaux et des Procédés, Grenoble INP-CNRS-UJF, BP 75, 38402 Saint Martin D'Hères, France. Tel.: +33 476826530; fax: +33476826677.

E-mail address: arnaud.claudel@simap.grenoble-inp.fr (A. Claudel).
}

(high electron mobility transistors: HEMT) or surface acoustic waves (SAW) emitters and detectors.

To date, most of the works dedicated to AlN bulk crystal growth have implemented the powder sublimation method (PVT) [1-3]. In 1959, Renner [4] grew the first AlN layers by CVD. Then, AlN epitaxial layers were obtained by reaction between anhydrous aluminum chloride and ammonia in 1967 and 1968 [5,6] or by direct reaction of the adduct compound $\mathrm{AlCl}_{3} \cdot \mathrm{NH}_{3}$ between 1970 and 1977 [7-9]. Since 1972, epitaxial growth of AlN on Sapphire and $\mathrm{SiC}$ substrates by a vapor phase epitaxy process using $\mathrm{Al}, \mathrm{HCl}$ and $\mathrm{NH}_{3}$ have been studied at temperature of about $1100^{\circ} \mathrm{C}$ [10-28]. Since 2007, several studies have been investigated to increase AIN layers crystalline quality and growth rate by increasing deposition temperature [29-35]. MOCVD epitaxial growth using trimethyl aluminum (TMA) and $\mathrm{NH}_{3}$ was also investigated at $1200{ }^{\circ} \mathrm{C}$ and AlN layers of high crystalline quality can be obtained but at low growth rate $\left(3 \mu \mathrm{m} \mathrm{h}^{-1}\right)$ [36,37]. In this 
work, a high temperature CVD process is explored to achieve high growth rate and high quality thick layers and later AIN single crystal bulk growth.

\section{Thermodynamic analysis}

Complex equilibria thermodynamic analysis of AIN HTCVD process was carried out using a procedure based on minimization of the whole Gibbs energy [38] with Factsage TM(C) using SGTE [39] and FACT [40] thermodynamic databases. Let us note that thermodynamic data for the condensed phase $\langle A I N\rangle$ are extrapolated when $T>930^{\circ} \mathrm{C}$ [41].

Our AlN HTCVD process consists in two steps. The first step is the synthesis of aluminum chlorides via the in situ reaction between $\mathrm{Cl}_{2}$ and $\mathrm{Al}$ (chlorination reaction). The second step is the deposition step which correspond to the chemical reaction between $\mathrm{AlCl}_{x}$ species and $\mathrm{NH}_{3}$ with either $\mathrm{H}_{2}$ or $\mathrm{Ar}$ as carrier gas.

Fig. 1 shows the effect of temperature at $P=10^{-2}$ atm (a) and pressure at $T=650{ }^{\circ} \mathrm{C}$ (b) on the formation of different $\mathrm{AlCl}_{x}$

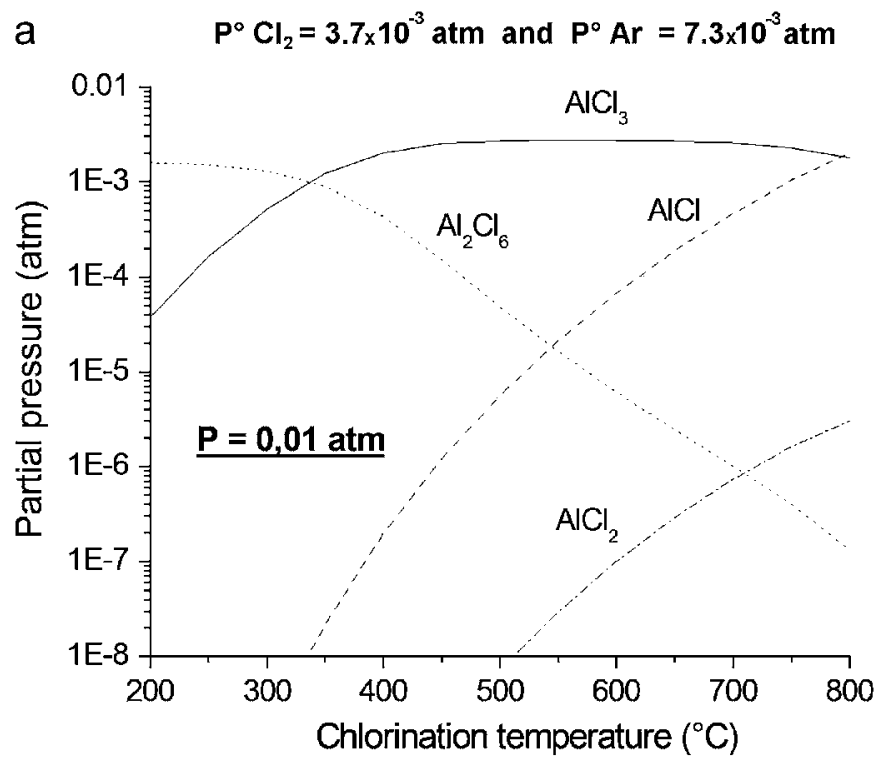

b

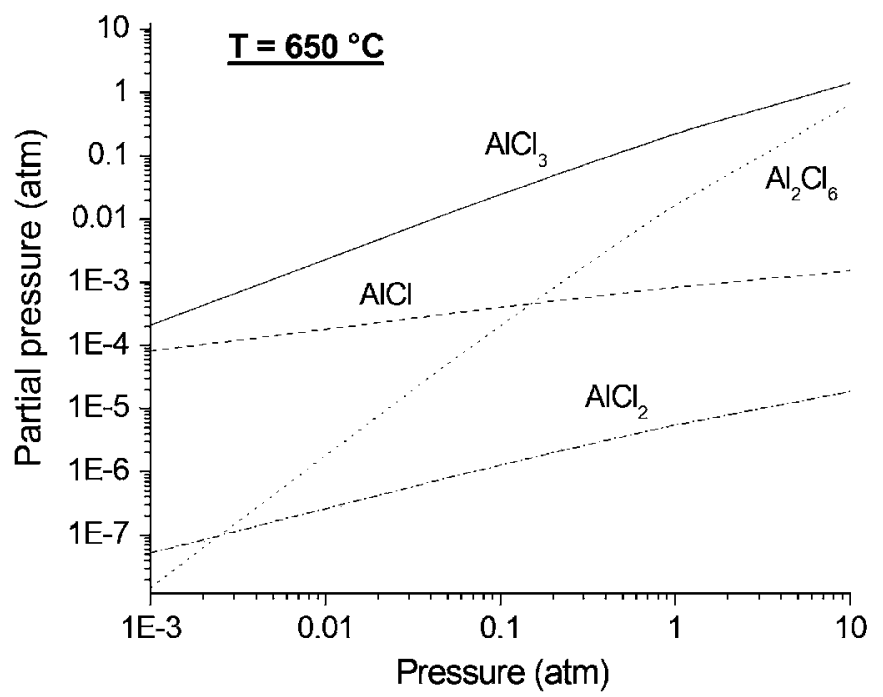

Fig. 1. Thermodynamic calculations on $\mathrm{AlCl}_{x}$ partial pressures vs. temperature at $10^{-2}$ atm (a) and total pressure at $650^{\circ} \mathrm{C}$ (b). species by reaction between $\mathrm{Al}$ and $\mathrm{Cl}_{2}$. It appears that equilibrium partial pressure of $\mathrm{AlCl}_{3}$ is larger than that of $\mathrm{AlCl}$ below $790^{\circ} \mathrm{C}$ and that $\mathrm{AlCl}$ and $\mathrm{AlCl}_{2}$ only exist at high temperature above $500{ }^{\circ} \mathrm{C}$ (Fig. 1(a)). Concerning the effect of total pressure (Fig. 1(b)), the increasing of $\mathrm{AlCl}_{3}$ and $\mathrm{AlCl}_{2}$ partial pressures is similar while the $\mathrm{Al}_{2} \mathrm{Cl}_{6} / \mathrm{AlCl}$ ratio exhibits a strong increase with a crossover at about $0.2 \mathrm{~atm}$. This thermodynamic study of $\mathrm{Al}$ chlorination by $\mathrm{Cl}_{2}$ is in agreement with previous thermodynamic calculations of reaction between $\mathrm{Al}$ and $\mathrm{HCl}$ $[17,18]$.

Such thermodynamic calculations indicate that $\mathrm{AlCl}_{x}$ species formed by chlorination remain stable between 500 and $1500{ }^{\circ} \mathrm{C}$. Above $1500{ }^{\circ} \mathrm{C}, \mathrm{AlCl}_{3}$ partial pressure decreases rapidly while $\mathrm{AlCl}$ (and $\mathrm{AlCl}_{2}$ ) partial pressure increases. Fig. 2 shows the thermodynamic study of homogeneous reactions in the gas phase (starting from $\mathrm{AlCl}_{x}$ synthesis at $T=650^{\circ} \mathrm{C}, \mathrm{NH}_{3}, \mathrm{H}_{2}, \mathrm{Ar}$ and without formation of any condensed phase). This indicates that $\mathrm{AlCl}$ plays an important role at high temperature above $1100{ }^{\circ} \mathrm{C}$. Above $1200{ }^{\circ} \mathrm{C}, \mathrm{AlCl}_{3}$ partial pressure decreases while those of $\mathrm{AlCl}$ and $\mathrm{AlCl}_{2}$ increase. $\mathrm{AlCl}$ partial pressure becomes larger than that of $\mathrm{AlCl}_{3}$ above $1450{ }^{\circ} \mathrm{C}$. $\mathrm{Al}_{2} \mathrm{Cl}_{6}$ and $\mathrm{AlCl}_{2} \mathrm{H}$ partial pressures decrease rapidly whereas those of $\mathrm{AlCl}_{2}$ and $\mathrm{Al}$ (gas) increase strongly at high temperature. But these other $\mathrm{Al}-$ reactants are negligible (less than $1 \%$ ). So, $\mathrm{AlCl}_{3}$ and $\mathrm{AlCl}$ seem to be the most important Al sources in HTCVD process at low temperature (above $500{ }^{\circ} \mathrm{C}$ ) and high temperature (above $1500{ }^{\circ} \mathrm{C}$ ), respectively. $\mathrm{H}_{2}$ remains stable but decreases slowly at high temperature to the advantage of $\mathrm{H}, \mathrm{HCl}$ and also $\mathrm{Cl}$ which increase strongly with increasing temperature. $\mathrm{H}$ and $\mathrm{Cl}$ appear only above $1100{ }^{\circ} \mathrm{C} . \mathrm{NH}_{3}$ partial pressure is very low and does not appear in Fig. 2. Thermodynamically, $\mathrm{NH}_{3}$ is rapidly dissociated in $\mathrm{N}_{2}$ and $\mathrm{H}_{2}$ when the temperature increases $\left(P_{\mathrm{NH}_{3}} \approx 10^{-9}\right.$ atm at $300{ }^{\circ} \mathrm{C}$ ). In these calculations, $\mathrm{NH}_{3}$ thermal dissociation is not inhibited so $\mathrm{N}_{2}$ seems to be the only one $\mathrm{N}$-reactant of this process which is not in good agreement with $\mathrm{N}_{2}$ actual high thermal stability. But it is well known that $\mathrm{NH}_{3}$ dissociation is catalyzed by metals and hindered by ceramicslike quartz $\left(\mathrm{SiO}_{2}\right)$ [42]. Furthermore, in previous thermodynamic studies, $\mathrm{NH}_{3}$ dissociation was sometimes not considered because of this kinetic aspect [42] or of the formation of an adduct compound in gas phase such as $\mathrm{AlCl}_{3} \cdot \mathrm{NH}_{3}[12,41-43]$ or $\mathrm{Cl}_{2} \mathrm{AlNH}_{2}[44,45]$. To

$\mathrm{AICl}_{\mathrm{x}}$ synthesis at $650^{\circ} \mathrm{C}$ and $10^{-2} \mathrm{~atm} ; \mathrm{P}^{\circ} \mathrm{NH}_{3}=3 \times 10^{-3} \mathrm{~atm}$ $\mathrm{P}^{\circ} \mathrm{H}_{2}=1.3 \times 10^{-3} \mathrm{~atm} ; \mathrm{P}^{\circ} \mathrm{Ar}=4.2 \times 10^{-3} \mathrm{~atm}$

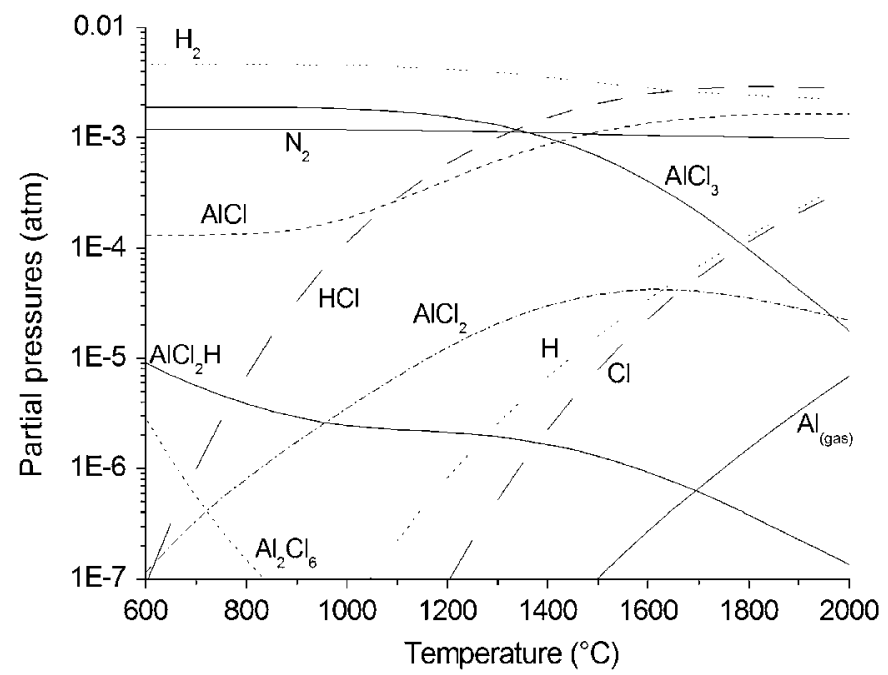

Fig. 2. Thermodynamic study of homogeneous reactions in the gas phase between 600 and $2000^{\circ} \mathrm{C}\left(P=10^{-2} \mathrm{~atm}\right)$. 
conclude on this point, kinetically, $\mathrm{NH}_{3}$ (and perhaps $\mathrm{NH}_{2}$ or $\mathrm{NH}$ at high temperature) seems to be the most important $\mathrm{N}$ source of AIN HTCVD.

The contribution of $\mathrm{AlCl}$ and $\mathrm{AlCl}_{3}$ on $\mathrm{AlN}$ deposition step between 600 and $2000{ }^{\circ} \mathrm{C}$ was also studied in $\mathrm{N}_{2}$ or $\mathrm{NH}_{3}$ atmosphere starting from the four following equations:

$3 \mathrm{AlCl}+\mathrm{N}_{2} \rightleftharpoons 2\langle\mathrm{AlN}\rangle+\mathrm{AlCl}_{3}$

$2 \mathrm{AlCl}_{3}+\mathrm{N}_{2} \rightleftharpoons 2\langle\mathrm{AlN}\rangle+3 \mathrm{Cl}_{2}$

$\mathrm{AlCl}+\mathrm{NH}_{3} \rightleftharpoons\langle\mathrm{AlN}\rangle+\mathrm{HCl}+\mathrm{H}_{2}$

$\mathrm{AlCl}_{3}+\mathrm{NH}_{3} \rightleftharpoons\langle\mathrm{AlN}\rangle+3 \mathrm{HCl}$

Thermodynamic AlN deposition yield $\eta$ was calculated with the following formula:

$\eta=\frac{n\langle\mathrm{AlN}\rangle}{\sum n \mathrm{AlCl}_{x} \text { initial }} \times 100$

Using $\mathrm{N}_{2}$ as $\mathrm{N}$ source, AlN synthesis cannot be realized with only $\mathrm{AlCl}_{3}$ (Eq. (2)) but is thermodynamically possible with $\mathrm{AlCl}$ (Eq. (1)). In the second case, both $\mathrm{AlCl}$ and $\mathrm{AlCl}_{3}$ can react with $\mathrm{NH}_{3}$ to form AlN (Eqs. (3) and (4)) which shows the great importance of $\mathrm{H}$ in this CVD process. Results of our thermodynamic calculations indicate that in both cases the use of a $\mathrm{AlCl}-\mathrm{AlCl}_{3}$ mixture improves AlN deposition yield than $\mathrm{AlCl}_{3}$ alone. AlN deposition from $\mathrm{AlCl}_{3}$ and $\mathrm{NH}_{3}$ decreases near $1200^{\circ} \mathrm{C}$ and seems to be impossible above $1300^{\circ} \mathrm{C}$ without $\mathrm{AlCl}$. With $\mathrm{AlCl}$ species, AlN deposition is thermodynamically possible until $1600{ }^{\circ} \mathrm{C}$. The decrease of AlN deposition at high temperature is due to the formation of the $\mathrm{AlCl}+2 \mathrm{HCl}+\frac{1}{2} \mathrm{~N}_{2}+\frac{1}{2} \mathrm{H}_{2}$ gas mixture, which is the most stable combination for gaseous species at high temperature $[44,46]$. However, in our experiments, AIN deposition was realized until $1800^{\circ} \mathrm{C}$ which contradicts the thermodynamic impossibility on AlN growth above $1600^{\circ} \mathrm{C}$. An explanation could be that experimental thermodynamic data on AlN above $930^{\circ} \mathrm{C}$ [41] and other compounds such as $\mathrm{AlCl}_{3} \cdot \mathrm{NH}_{3}[12,42,43]$ are not available. Furthermore, the existence of a $\mathrm{Cl}_{2} \mathrm{AlNH}_{2}$ species which is also not included in these calculations is supposed by ab-initio calculations above $600-700{ }^{\circ} \mathrm{C}[44]$ and by analogy with $\mathrm{Cl}_{2} \mathrm{BNH}_{2}$ [45,47-49] (coming from direct reaction in gas phase between $\mathrm{BCl}_{3}$ and $\mathrm{NH}_{3}$ ) which was measured by HT mass spectrometry measurements in CVD conditions and seems to be a key species in BN deposition process [50,51].

Fig. 3(a) shows AlN deposition yield as a function of $\mathrm{AlCl}_{3}$ and $\mathrm{NH}_{3}$ partial pressures at $1100{ }^{\circ} \mathrm{C}$ and $10^{-2} \mathrm{~atm}$. The maximum AlN deposition yield is found for a low $\mathrm{AlCl}_{3}$ partial pressure and a high $\mathrm{NH}_{3}$ partial pressure. Fig. 3(b) shows AlN deposition yield as a function of $\mathrm{AlCl}_{3}$ and $\mathrm{H}_{2}$ partial pressures at $1100^{\circ} \mathrm{C}$ and $10^{-2} \mathrm{~atm}$. AlN yield increases with increasing $\mathrm{H}_{2}$ partial pressure at constant $\mathrm{AlCl}_{3}$ and $\mathrm{NH}_{3}$ partial pressures. Thermodynamically, the use of $\mathrm{H}_{2}$ carrier gas promotes the formation of AlN compared to an inert gas such as Ar.

The influence of a variation to thermodynamic equilibrium defined as gas phase supersaturation was also studied. Experimentally, a variation of supersaturation in gas phase is known to have a great effect on surface morphology and crystallographic orientation of deposits. Usually, the epitaxial growth is favored with a low supersaturation [52,53]. In the case of AlN a low supersaturation is obtained at high temperature and for partial pressures of reactants near the thermodynamic equilibrium. In the present investigations, supersaturation $\alpha$ was calculated with the following formula:

$\alpha=\frac{P_{\mathrm{Al} \text { species }} \times P_{N \text { species }}}{P_{\text {eq Al species }} \times P_{\text {eq } N \text { species }}}$ a

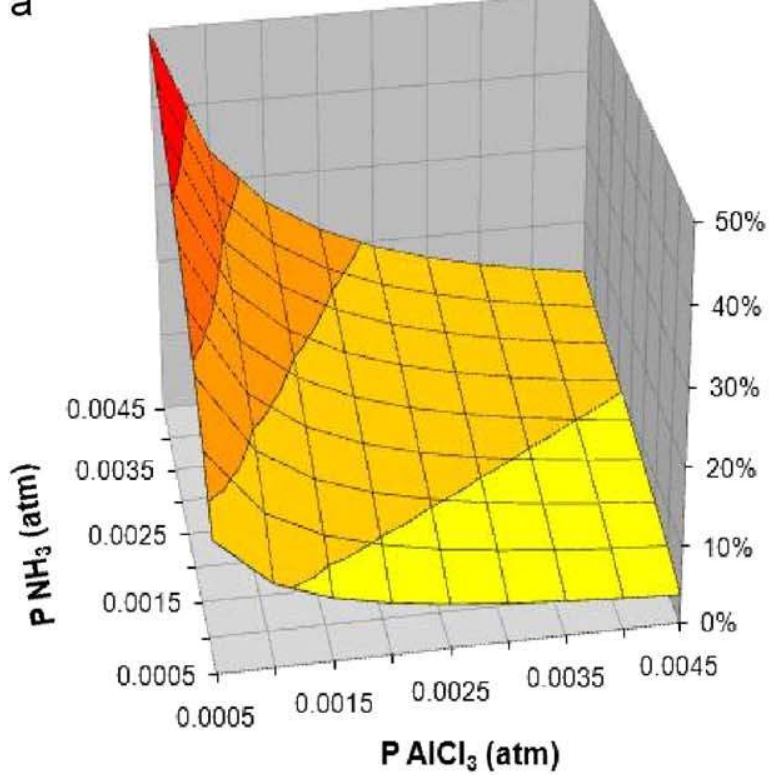

b

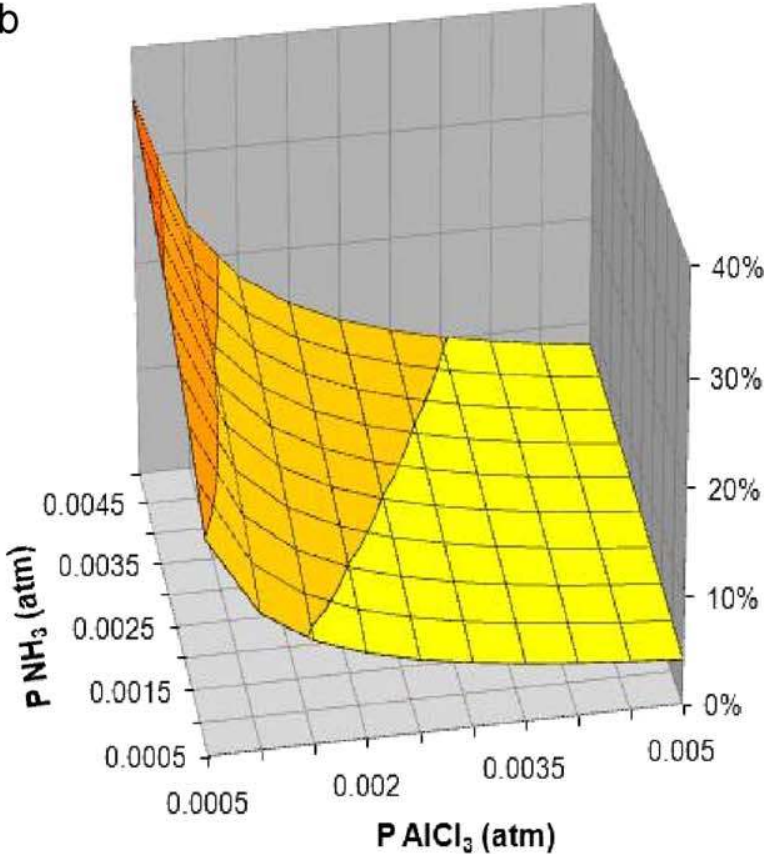

$z \frac{\substack{\frac{0}{0} \\ \frac{0}{2}}}{\frac{c}{2}}$

Fig. 3. AlN deposition yield vs. $\mathrm{AlCl}_{3}$ and $\mathrm{NH}_{3}$ partial pressures (a) and $\mathrm{AlCl}_{3}$ and $\mathrm{H}_{2}$ partial pressures (b) at $T=1100^{\circ} \mathrm{C}$ and $P=10^{-2} \mathrm{~atm}$.

where $P$ is the partial pressure of reactant species and $P_{e q}$ is the calculated thermodynamic equilibrium partial pressure of $\mathrm{Al}$ and $\mathrm{N}$ species over solid AlN at given temperature and total pressure.

Fig. 4 shows calculated gas phase supersaturation $\alpha$ between 1000 and $2000{ }^{\circ} \mathrm{C}$ at $10^{-2}$ atm with different $\mathrm{H}_{2} / \mathrm{AlCl}_{3}$ ratio at a constant $\mathrm{NH}_{3}$ partial pressure. Supersaturation decreases rapidly with increasing temperature and slowly with increasing $\mathrm{H}_{2} / \mathrm{AlCl}_{3}$ ratio.

Our thermodynamic calculations indicate that $\mathrm{AlCl}$ is a necessary precursor to grow AlN at high temperature with high growth rate, it is also known that $\mathrm{AlCl}$ is very reactive with quartz $\left(\mathrm{SiO}_{2}\right)$ reactor and this reaction is accelerated in the presence of $\mathrm{H}_{2}$ [11]. For this reason, $\mathrm{AlCl}_{3}$ is generally favored and generated by decreasing the temperature of the chloride source at $500{ }^{\circ} \mathrm{C}$ $[17,18,20,21,23,24,27,28]$. In our case, a water-cooled quartz tube (and a reactants dilution) prevent the reaction of $\mathrm{AlCl}$ with quartz. 


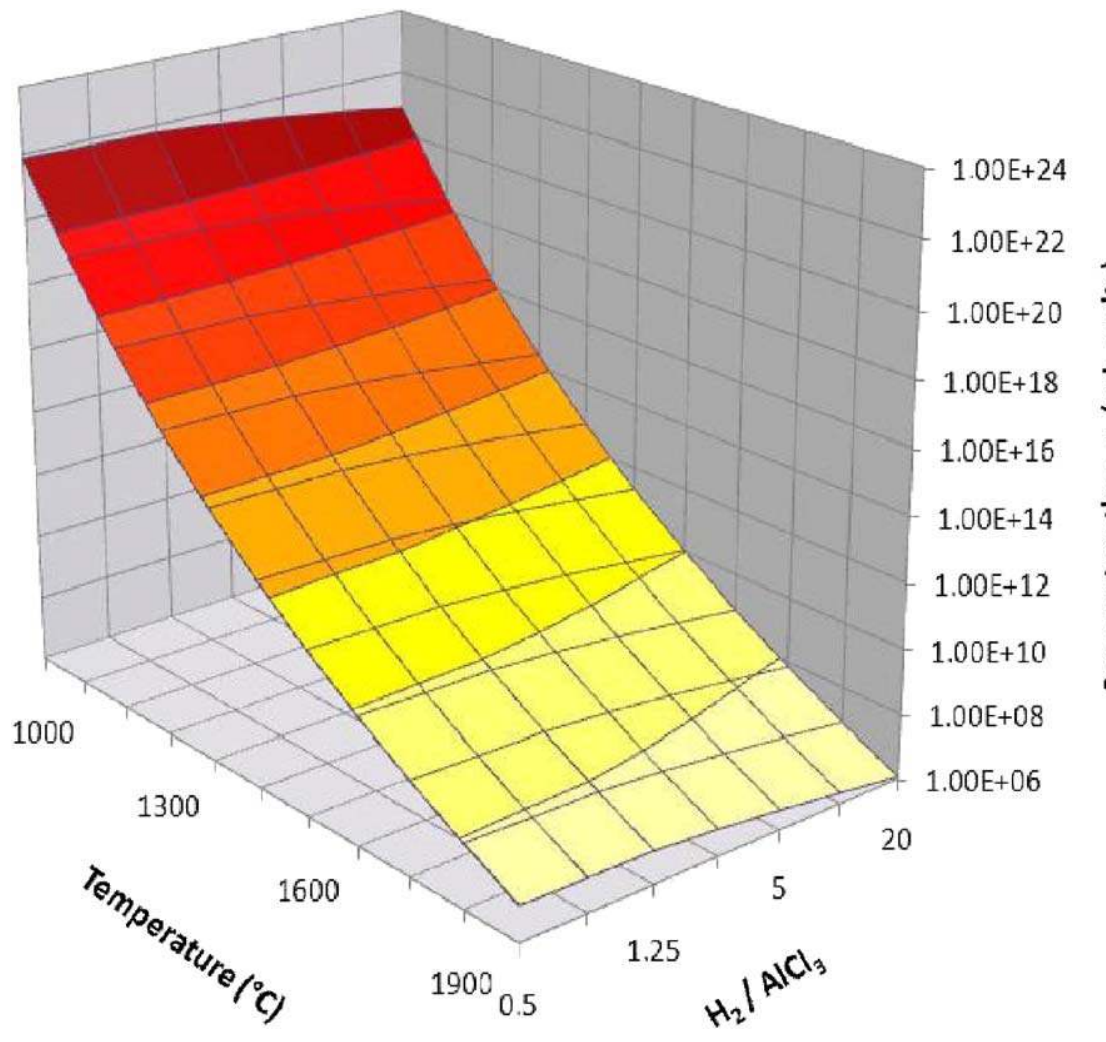

Fig. 4. Influence of temperature and $\mathrm{H}_{2} / \mathrm{AlCl}_{3}$ ratio on calculated supersaturation $\alpha$ (constant $\mathrm{NH}_{3}$ partial pressure).

Based on these thermodynamic calculations of $\mathrm{AlCl}_{x}$ synthesis and AlN deposition step, it is possible to grow AIN by HTCVD at low pressure in a water-cooled quartz reactor.

\section{Experimental procedure}

A schematic diagram of the HTCVD apparatus is shown in Fig. 5. The HTCVD set-up consists in a home-built vertical coldwall reactor composed of two reaction zones [35,54]. The first one is the chlorination area where aluminum chlorides are generated via in situ reaction at $640^{\circ} \mathrm{C}\left(T_{\text {melt }} . \mathrm{Al}=660^{\circ} \mathrm{C}\right)$ between $\mathrm{Cl}_{2}$ and high purity $\mathrm{Al}$ wire contained in an inner tube heated by a lamp furnace. Then, $\mathrm{AlCl}_{x}$ species are mixed with $\mathrm{NH}_{3}$ and either $\mathrm{H}_{2}$ or $\mathrm{Ar}$ as carrier gas. The second zone whose walls are water-cooled is the AlN deposition area. The substrate is located on top of a graphite susceptor heated by induction and the deposition temperature is measured on the graphite surface using InfraRed pyrometry. The $\mathrm{NH}_{3}$ flow is in a $(20-100 \mathrm{sccm})$ range and diluted in $200-1000 \mathrm{sccm}$ of $\mathrm{Ar}$ or $\mathrm{H}_{2}$. The $\mathrm{Cl}_{2}$ flow rate is fixed between 2.5 and $100 \mathrm{sccm}$ and diluted with Ar.

AlN films were deposited at low pressure on $\left(\begin{array}{llll}0 & 0 & 0 & 1\end{array}\right) \alpha-\mathrm{Al}_{2} \mathrm{O}_{3}$ Sapphire and (0001) off axis $4 \mathrm{H} \mathrm{SiC}$ or on axis $6 \mathrm{H} \mathrm{SiC}$ single crystals between 1100 and $1800^{\circ} \mathrm{C}$. Let us note that a reaction occurs between $\mathrm{Al}_{2} \mathrm{O}_{3}$ and $\mathrm{C}$ above $1500{ }^{\circ} \mathrm{C}$ which induces the formation of $\mathrm{CO}, \mathrm{Al}_{2} \mathrm{O}$ and $\mathrm{Al}$ gases in agreement with our thermodynamic calculations and a previous study of the Al-C-O ternary system [55]. Before AlN deposition, Sapphire and SiC substrates were chemically etched in a HF $5 \%$ solution for $10 \mathrm{~min}$. A thermal cleaning under $\mathrm{H}_{2}$ atmosphere was also carried out above $1000^{\circ} \mathrm{C}$ for $15 \mathrm{~min}$. As-grown AlN layers surface morphologies were studied by SEM, FEG-SEM and AFM. Crystalline state, crystallographic orientations and epitaxial relationships with substrates were obtained from $\theta / 2 \theta$ X-ray diffraction and X-ray pole figure, respectively.

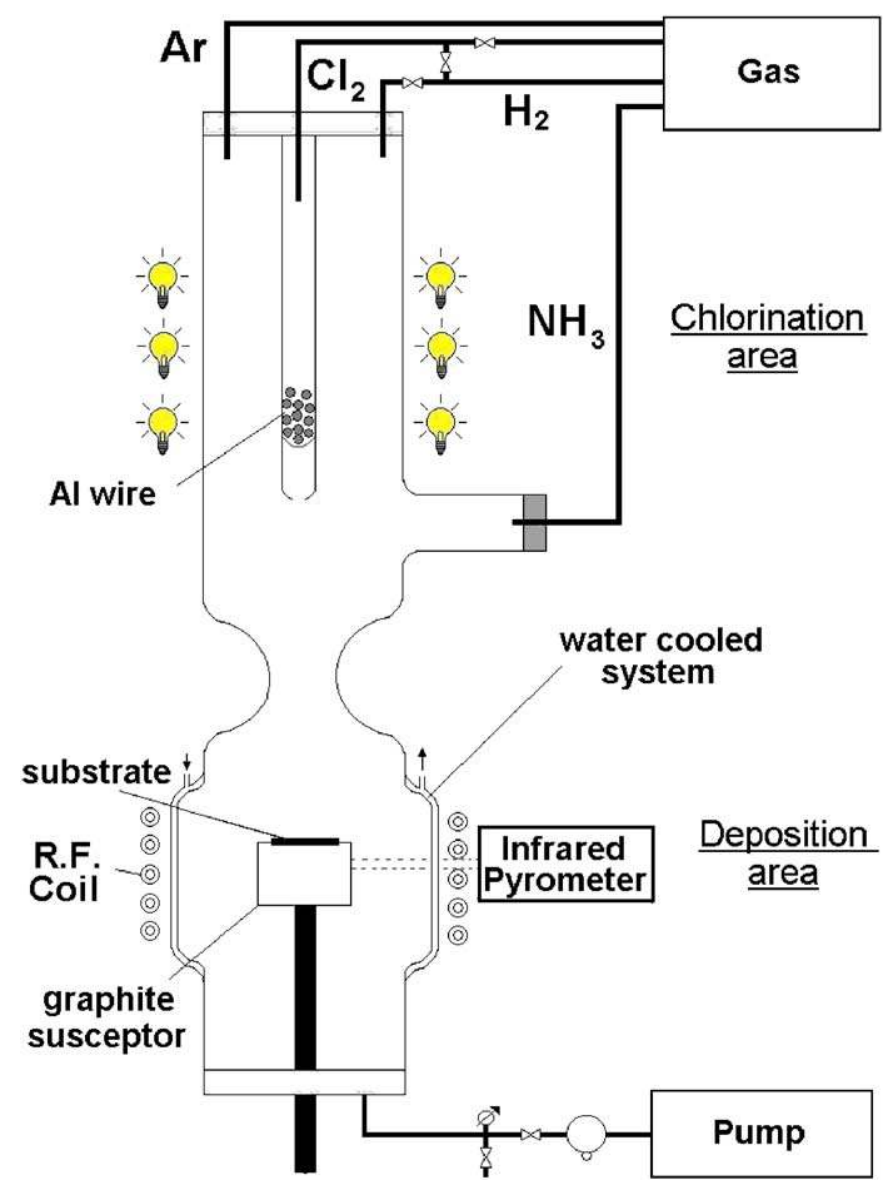

Fig. 5. High temperature CVD quartz reactor. 


\section{Results and discussions}

In this experimental investigation, AlN films were deposited at different temperatures, in a range of $1100-1800{ }^{\circ} \mathrm{C}$ on different single crystal substrates: (0 0001$) \mathrm{Al}_{2} \mathrm{O}_{3},\left(\begin{array}{lll}0 & 0 & 01\end{array}\right)$ off axis $4 \mathrm{H} \mathrm{SiC}$ and on axis $6 \mathrm{H} \mathrm{SiC} \mathrm{[35].} \mathrm{Different} \mathrm{conditions} \mathrm{were} \mathrm{tested} \mathrm{in} \mathrm{order}$ to reach epitaxial growth. The influence of growth temperature, total pressure and chlorine flow rate were studied. Films morphology is also related to a variation of the thermodynamic supersaturation. Crack-free polycrystalline AlN layers were obtained with a thickness up to $150 \mu \mathrm{m}$ and growth rates up to $200 \mu \mathrm{m} \mathrm{h}^{-1}$. Their color varied from white to yellow and to brown with increasing $\mathrm{Cl}_{2}$ flow rate. Yellow and brown colors of deposits seem to be related to an enrichment by aluminum in AIN interstitial sites $[3,11,12]$. Mirror-like AlN layers were grown up to a thickness of $30 \mu \mathrm{m}$ but exhibited cracks. Any chlorine has not been found from X-EDS in all fabricated AlN films.

Fig. 6(a) is the typical kinetic curve which shows the variation of AlN growth rate on $4 \mathrm{H} \mathrm{SiC}$ substrates as a function of the inverse of temperature in the $1100-1800{ }^{\circ} \mathrm{C}$ range at $P=10$ Torr. Growth rate varied from 10 to $30 \mu \mathrm{m} \mathrm{h}^{-1}$. At low temperature, this curve represents the kinetic regime of AlN deposition. High growth rates are obtained at high temperature which correspond to the diffusion regime [52]. A slight drop of deposition rate is observed at very high temperature and probably corresponds to the decrease of thermodynamic supersaturation (Fig. 4) and/or the beginning of powder formation by homogeneous nucleation in the gas phase [52,56-58]. Contrary to thermodynamic prediction, we definitely observed the formation of condensed AlN above $1600{ }^{\circ} \mathrm{C}$. A new further assessment of thermodynamic data on the whole $\mathrm{Al}-\mathrm{N}-\mathrm{H}-\mathrm{Cl}$ system at high temperature should be achieved as for the $\mathrm{Si}-\mathrm{C}-\mathrm{H}-\mathrm{Cl}$ system [53,59-61]. Fig. 6(b) shows the variation of AlN growth rate as a function of total pressure at $1750{ }^{\circ} \mathrm{C}$. AlN deposition rate decreases with increasing pressure between 10 and 100 Torr as previously reported by Suzuki and Tanji [58] but for a temperature of $1000^{\circ} \mathrm{C}$. Our thermodynamic analysis shows that AlN growth rate increases as a logarithmic function with increasing total pressure. The experimental trend cannot be explained by a thermodynamic approach but probably by chemical reactions, kinetic, gas dynamics and/or reactor's design effects. Fig. 6(c) shows the variation of AlN growth rate as a function of $\mathrm{Cl}_{2}$ flow rate at $1750{ }^{\circ} \mathrm{C}$ and 10 Torr. Growth rate increases linearly with increasing $\mathrm{Cl}_{2}$ flow rate which is in agreement with our thermodynamic calculations. So, in these conditions, the deposition of AIN is probably limited by the formation of $\mathrm{AlCl}_{x}$ species, in agreement with previous investigations based on CVD using $\mathrm{AlCl}_{3}$ [9,46,58] and on hydride vapor phase epitaxy using the reaction between $\mathrm{HCl}$ and $\mathrm{Al}[20,21,24,28]$.

The effect of carrier gas ( $\mathrm{Ar}$ and/or $\mathrm{H}_{2}$ ) was also studied. The use of $\mathrm{H}_{2}$ as carrier gas allows to obtain higher growth rate as expected from thermodynamic calculations, more dense deposits and smoothest surface morphology than Ar. But it is still unclear if it comes from a chemical or a thermal effect.

Fig. 7 shows an X-ray diffraction pattern of preferred oriented (0001) 2H AlN film deposited on (0001) Sapphire substrate. From $\theta / 2 \theta$ scans related to diffracting vectors normal to the (0001) surface of $\alpha-\mathrm{Al}_{2} \mathrm{O}_{3}$ single crystal substrate, it has been deduced that each AlN sample exhibits a simple crystallographic orientational relationship with the substrate; i.e. $(0001)_{\mathrm{AIN}} / /(0001)_{\alpha-\mathrm{Al}_{2} \mathrm{O}_{3}}$ (Fig. $\left.7(\mathrm{a})\right)$. Let us recall that both the structure AlN and $\alpha-\mathrm{Al}_{2} \mathrm{O}_{3}$ are hexagonal $P 6_{3} m c(a=3.1114 \AA$, $c=4.9792 \AA)$ and trigonal $R-3 c(a=4.7617 \AA, c=12.9947 \AA$ or $a=4.7617 \AA$ and $\alpha=55.3004^{\circ}$ for rhombohedral axes), respectively. However, from systematic plots of $\log (I)=f(2 \theta)$, it could also be deduced that part of AlN layers were polycrystalline a

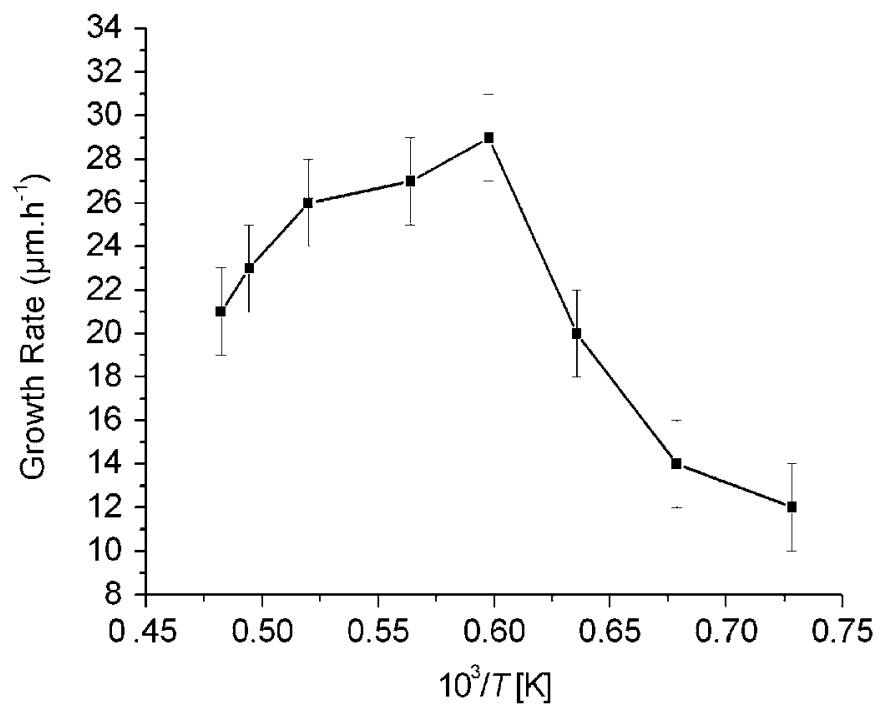

b

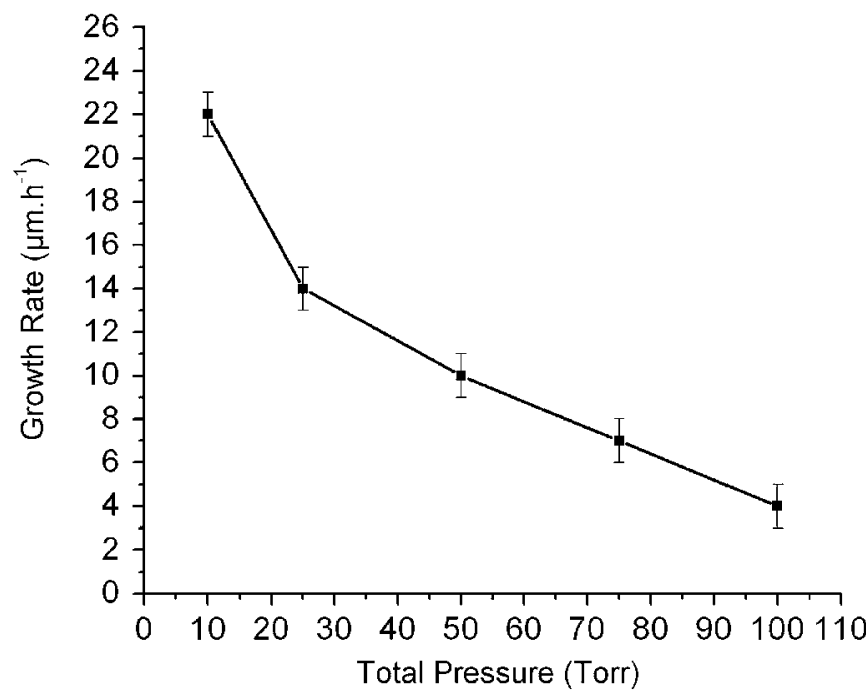

$\mathrm{C}$

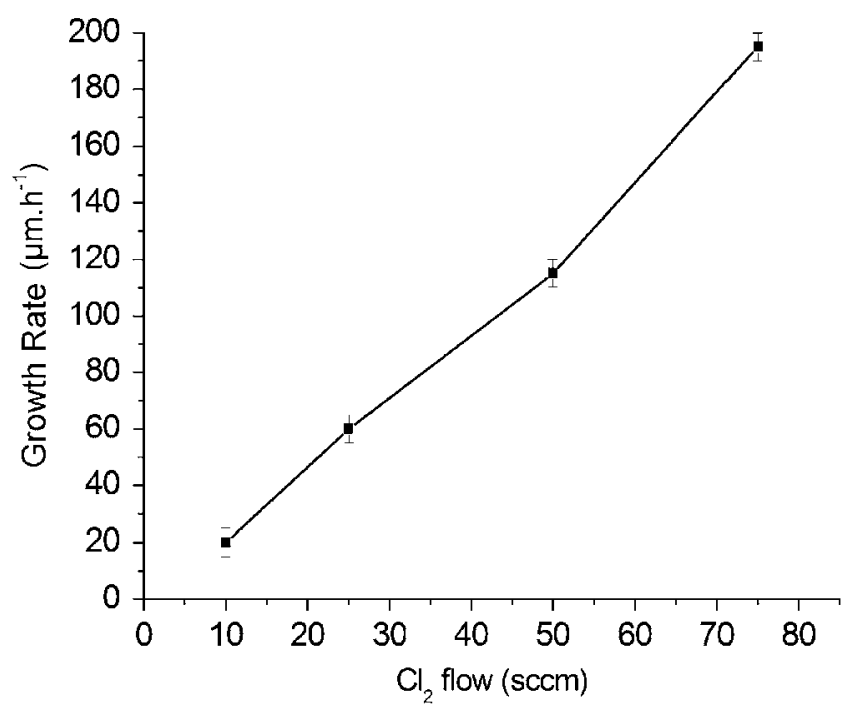

Fig. 6. Temperature (a), total pressure (b), and chlorine flow rate (c) effects on AlN growth rate on $(0001) 4 \mathrm{H} \mathrm{SiC}$ substrates. 
a

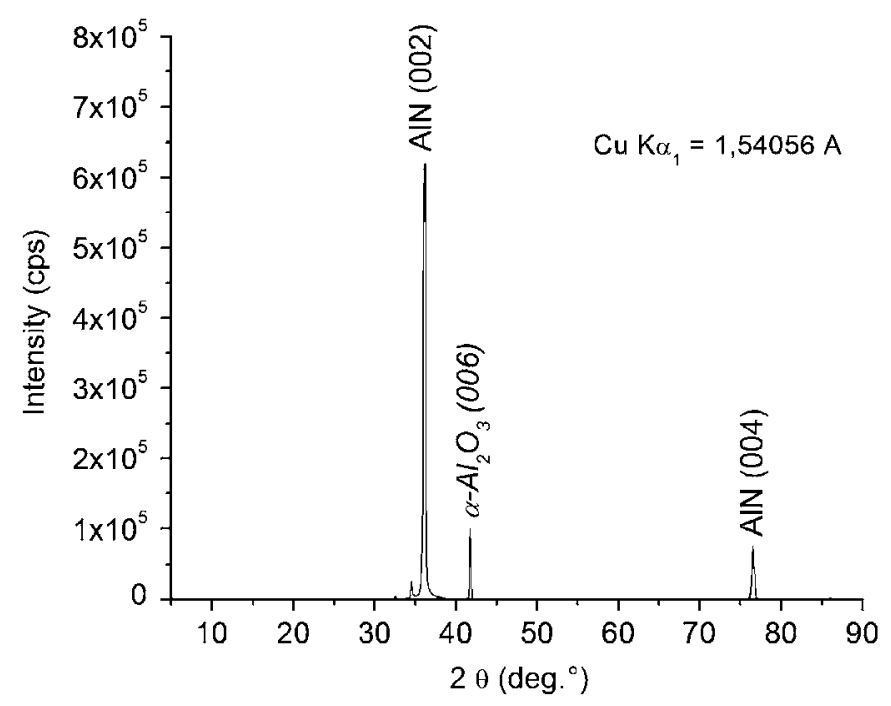

b

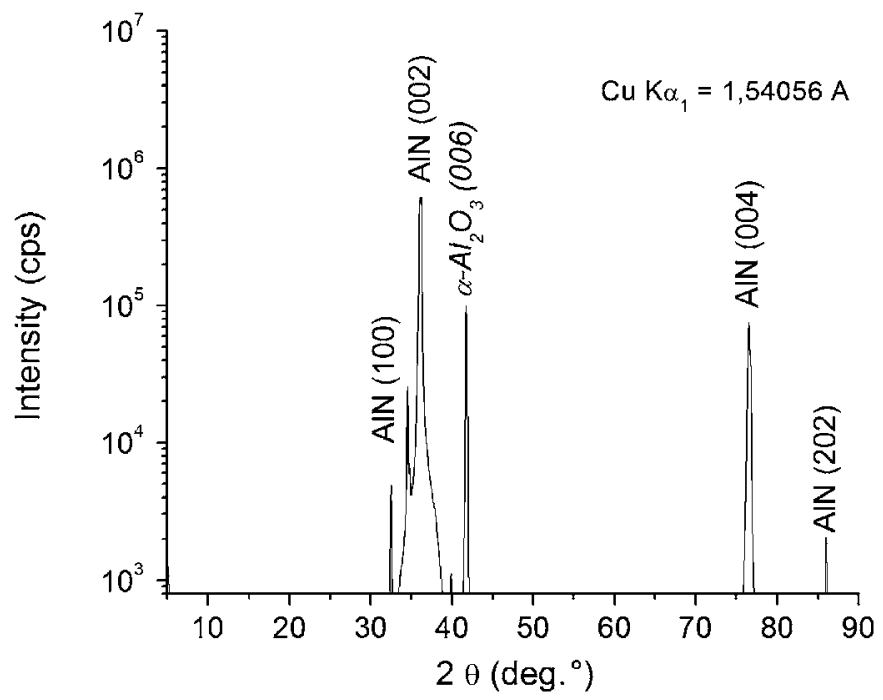

Fig. 7. Example of $\theta / 2 \theta$ X-ray diffraction pattern of an $2 \mathrm{H}$ AlN layer deposited on

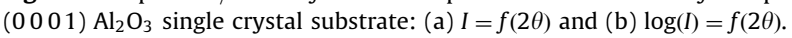

(Fig. 7(b)). Same conclusions has been found for films deposited on $4 \mathrm{H}$ and $6 \mathrm{H} \mathrm{SiC}$ single crystal substrates.

As the possibility of epitaxial relationships could be expected

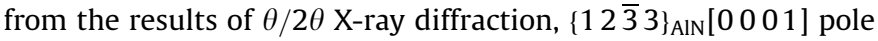
figures were determined using a texture goniometer in order to complete the characterization of crystallographic orientation of AlN layer with respect to its substrate, either $\left(\begin{array}{llll}0 & 0 & 0 & 1\end{array}\right) \mathrm{Al}_{2} \mathrm{O}_{3}$ or $(0001) 4 \mathrm{H}$ SiC. Such X-ray diffraction measurements were performed around the [0001] direction normal to the substrate up to a $\chi$ angle of $90^{\circ}$. The experimental results are represented on stereographic projections of [0 001 ] zone axis (Fig. 8). The $12 \overline{3} 3$ reflections of AlN $\left(\mathrm{d}_{12 \overline{3} 3}=0.868 \AA\right.$ ) being very close to the $4 \overline{4} 08$ (or 044 ) reflections of $\alpha-\mathrm{Al}_{2} \mathrm{O}_{3}$, we have fixed a $\Delta \theta$ resolution of $\pm 0.14^{\circ}$ in order to observe both these types of reflection from one $\varphi, \chi$ scan of 32,400 pointsonly. As a result, small intensities of $12 \overline{3} 6_{4 \mathrm{H} \mathrm{Sic}}$ and $10 \overline{1} 11_{4 \mathrm{H} \mathrm{Sic}}$, also very close to $12 \overline{3} 3_{\mathrm{AIN}}$ reflections, are observed on these scans. The indexing of $\alpha-\mathrm{Al}_{2} \mathrm{O}_{3}$ is related to rhombohedral axes which allows to identify the orientation of the threefold symmetry of this structure. The 044 reflections of $\alpha-\mathrm{Al}_{2} \mathrm{O}_{3}$ are represented by first order 011 reflections as they project on same positions as 044 reflections.
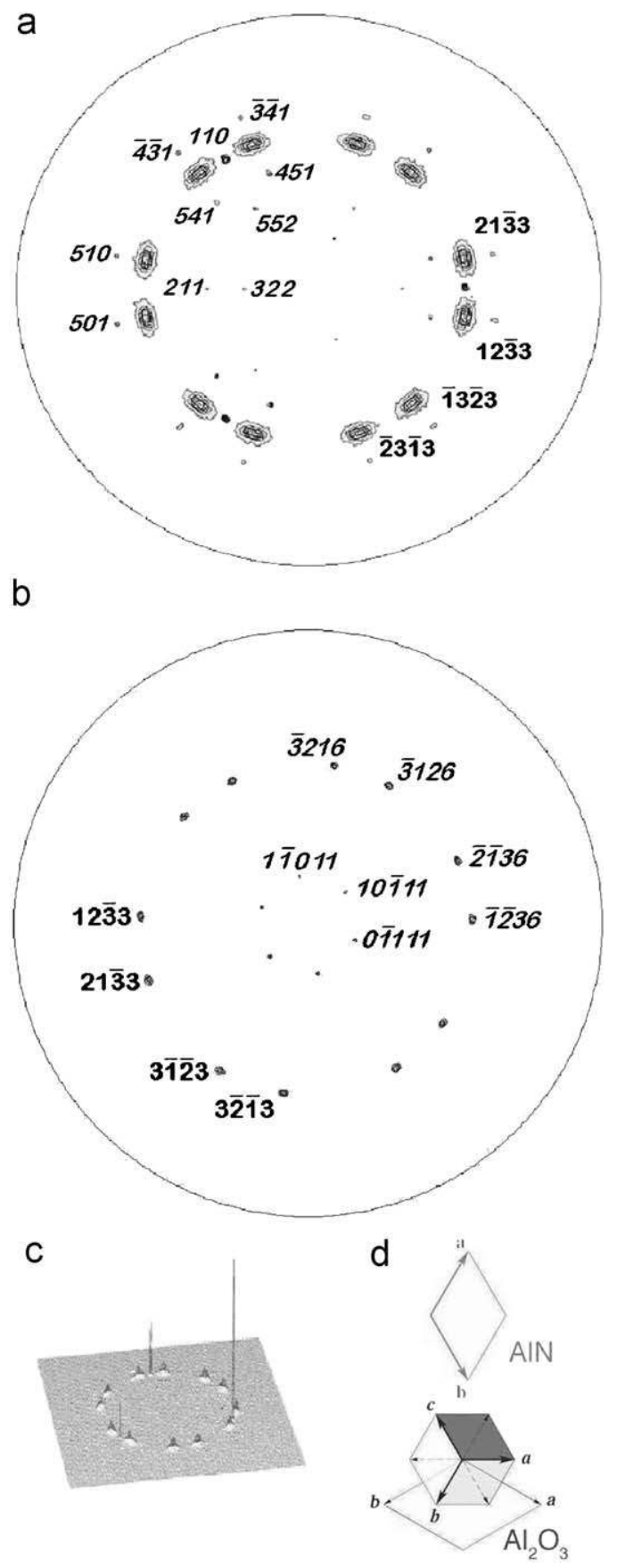

Fig. 8. Examples of $\{12 \overline{3} 3\}_{\text {AIN }}$ [0 001 ] pole figures of AlN layers deposited on

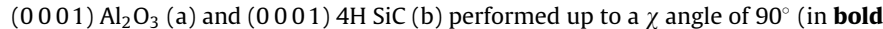
AlN reflexions, in italic Sapphire or $4 \mathrm{H} \mathrm{SiC}$ substrate reflexions); in insert (c) plot indicating the relative intensity between $12 \overline{3} 3_{\mathrm{AIN}}$ and $044_{\alpha-\mathrm{Al}_{2} \mathrm{O}_{3}}$ reflections (d) the relative orientation of both $\mathrm{AlN}$ and $\alpha-\mathrm{Al}_{2} \mathrm{O}_{3}$ cells.

Many other reflections of very weak intensity are also identified as corresponding to these of substrate $\alpha-\mathrm{Al}_{2} \mathrm{O}_{3}$. Then it is straightforward to deduce from these pole figures the following epitaxial relationships:

$\left[\begin{array}{lllll}0 & 0 & 0 & 1\end{array}\right]_{\mathrm{AIN}} / /\left[\begin{array}{llll}1 & 1 & 1\end{array}\right]$ or $\left[\begin{array}{llll}0 & 0 & 0 & 1\end{array}\right]_{\alpha-\mathrm{Al}_{2} \mathrm{O}_{3}}$

$\left[\begin{array}{llll}1 & \overline{1} & 0 & 0\end{array}\right]_{\mathrm{AIN}} / /\left[\begin{array}{lll}\overline{1} & 0 & 1\end{array}\right]$ or $\left[\begin{array}{llll}1 & 1 & \overline{2} & 0\end{array}\right]_{\alpha-\mathrm{Al}_{2} \mathrm{O}_{3}}$

$\left[\begin{array}{llllll}0 & 0 & 0 & 1\end{array}\right]_{\text {AIN }} / /\left[\begin{array}{llllll}0 & 0 & 0 & 1\end{array}\right]_{\text {SiC }}$

$\left[\begin{array}{llll}1 & \overline{1} & 0 & 0\end{array}\right]_{\mathrm{AIN}} / /\left[\begin{array}{llll}1 & \overline{1} & 0 & 0\end{array}\right]_{\mathrm{SiC}}$ 
With increasing the temperature of HTCVD process, we have observed that the $12 \overline{3} 3$ reflections of AlN become less broad and that the proportion of powder-like AIN diminishes.

The crystallinity of AlN layers in epitaxy on ( $\left.\begin{array}{llll}0 & 0 & 0 & 1\end{array}\right)$ off axis $4 \mathrm{H}$ $\mathrm{SiC}$ substrates was characterized using the $\omega$ scan method (rocking curves, RCs) [62,63]. X-ray rocking curves were measured on both 0002 and $10 \overline{1} 2$ AlN reflections in order to study out of plane (tilt) and in plane (twist) distortions, respectively. The lowest full-width at half-maximum (FWHM) values were $2100 \operatorname{arcsec}\left(0.58^{\circ}\right)$ for $(0002)$ and $1400 \operatorname{arcsec}\left(0.39^{\circ}\right)$ for $(10 \overline{1} 2)$ in the case of a $10 \mu \mathrm{m}$ AlN layer deposited in the following conditions: $T=1750^{\circ} \mathrm{C}, P=10$ Torr, low reactant flow rates and high carrier gas dilution. These values are important compared to those currently obtained on $\left(\begin{array}{lll}0 & 0 & 01\end{array}\right)$ on axis $6 \mathrm{H} \mathrm{SiC}$

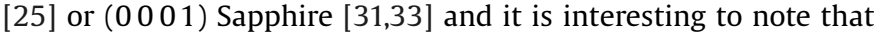
using this HTCVD process, tilt is more important than twist contrary to HVPE process [20,25,31,33].

Fig. 9 shows SEM images of AlN layers grown on $4 \mathrm{H} \mathrm{SiC}$ substrates at various deposition temperatures with constant partial pressure of reactants and a total pressure of 10 Torr. With decreasing the supersaturation by increasing the deposition

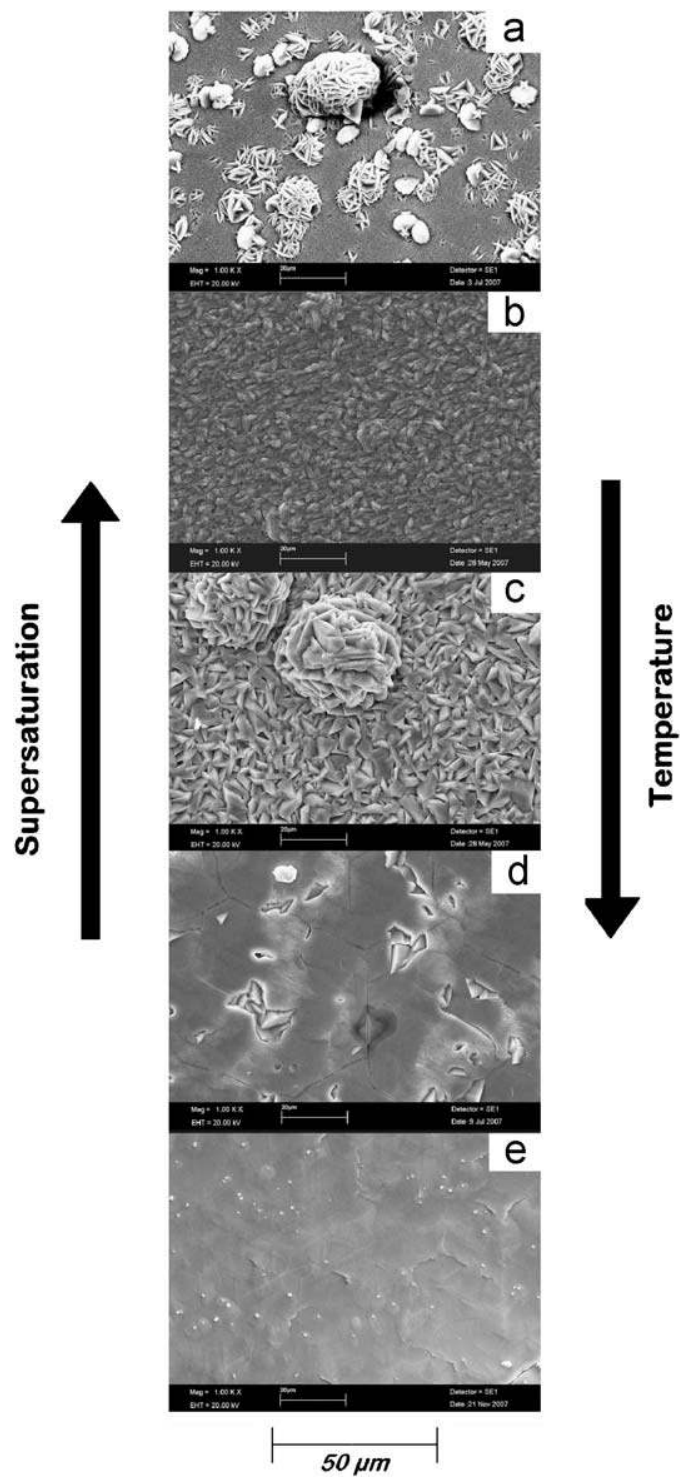

Fig. 9. SEM images of AlN layers grown on $4 \mathrm{H} \mathrm{SiC}$ substrates at $1100^{\circ} \mathrm{C}(\mathrm{a}), 1300^{\circ} \mathrm{C}$ (b), $1500{ }^{\circ} \mathrm{C}$ (c), $1650{ }^{\circ} \mathrm{C}$ (d) and $1750^{\circ} \mathrm{C}$ (e) (constant reactants partial pressures and $P=10$ Torr). temperature, the surface morphologies obtained are sphere-like and become facetted and then smooth. So, rougher deposits are obtained at low temperature and smooth films at high deposition temperature. These smooth AlN layers obtained at high temperature were related to the AlN epitaxial growth from the previous $\theta / 2 \theta \mathrm{X}$-ray diffraction and X-ray pole figure experiments. However, several cracks were observed on such smooth AlN layers probably because of the difference of thermal expansion

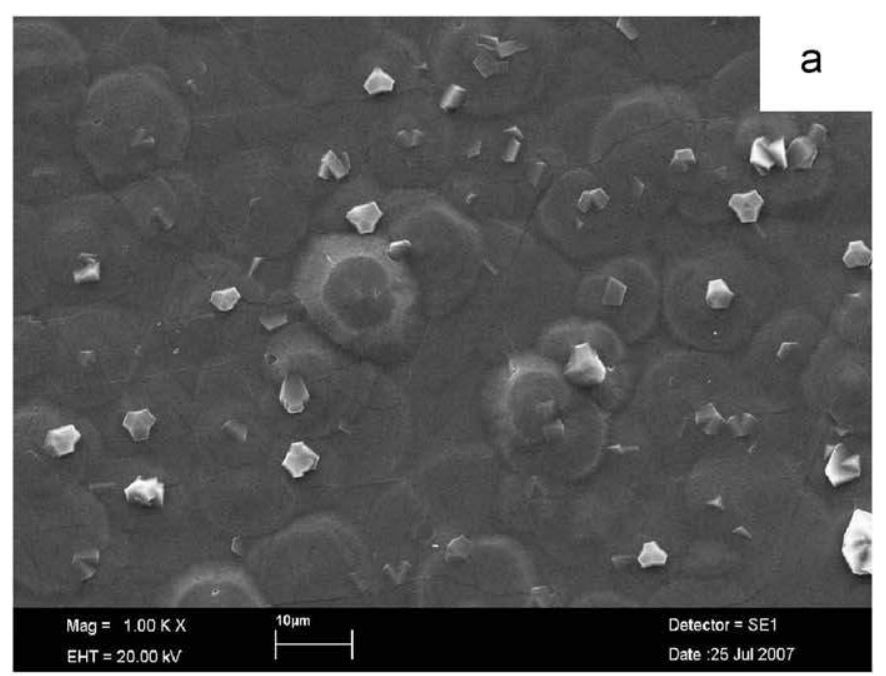

b

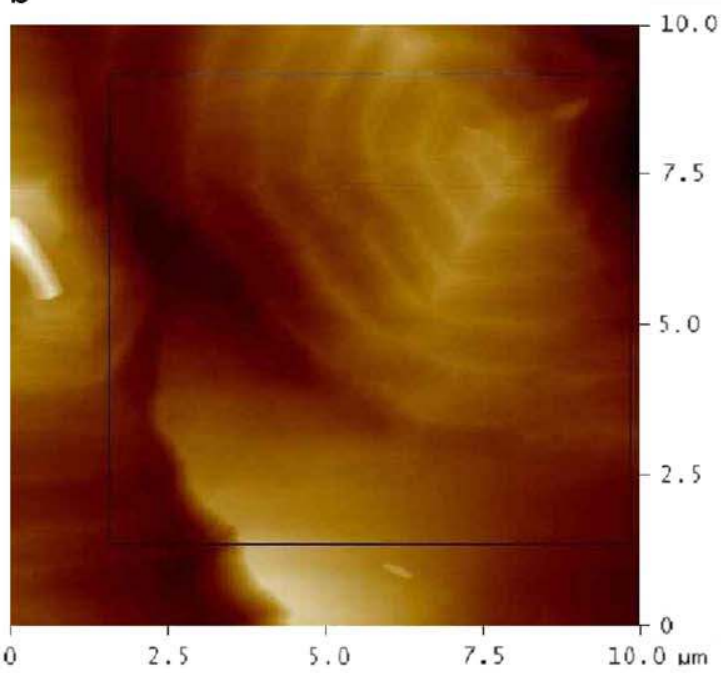

C

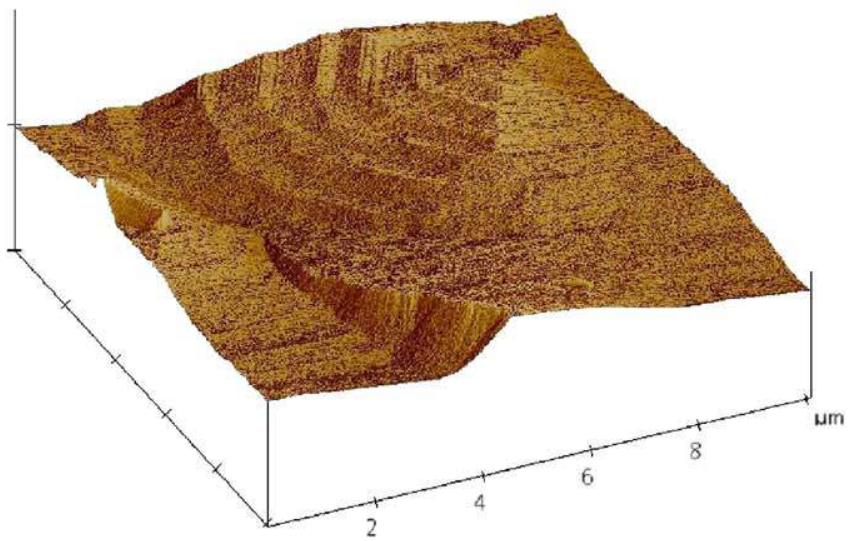

Fig. 10. SEM (a) and AFM ((b) and (c)) images of an AIN layer deposited at $1750{ }^{\circ} \mathrm{C}$ and 10 Torr on $6 \mathrm{H} \mathrm{SiC} \mathrm{(on} \mathrm{axis).}$ 
coefficient between AlN and the substrate at high temperature, lattice mismatch substrate-deposit and temperature ununiformity on the substrate surface.

Fig. 10 shows a SEM and AFM images of an AIN layer deposited at $1750{ }^{\circ} \mathrm{C}$ and $10 \mathrm{Torr}$ on $6 \mathrm{H} \mathrm{SiC} \mathrm{(on} \mathrm{axis).} \mathrm{This} \mathrm{AlN} \mathrm{layer} \mathrm{exhibits}$ hexagonal based hillocks (Fig. 10(a)). Those observed by AFM consist in polygonized spiral which very probably come from a preferential epitaxial growth around screw dislocations (Fig. 10(b) and (c)). Defect formation analysis, as done for SiC growth [64,65], should be very useful to understand the growth mechanisms. This growth mode is related to low supersaturation conditions and epitaxial growth. RMS roughness between 20 and $35 \mathrm{~nm}$ was obtained for such AlN layers.

\section{Conclusions}

Thermodynamic calculations on $\mathrm{AlCl}_{x}$ synthesis and $\mathrm{AlN}$ deposition step indicate that it is possible to grow AIN by HTCVD at low pressure in a water-cooled quartz reactor. $\mathrm{AlCl}_{3}$ and $\mathrm{AlCl}$ seem to be the most important Al-reactant in HTCVD process at low temperature and high temperature, respectively. However, several compounds formations by homogeneous reactions in gas phase and associated chemical mechanisms are still unclear. Experimentally, the growth of thick AlN layers on Sapphire and $\mathrm{SiC}$ substrates was achieved between 1100 and $1800^{\circ} \mathrm{C}$ by HTCVD. Experiments prove that the use of $\mathrm{H}_{2}$ as carrier gas instead of $\mathrm{Ar}$ allows to obtain higher growth rates, more dense deposits and smoothest surface morphologies. AlN epitaxial layers were grown when the deposition process was performed with low supersaturation conditions, i.e. high temperature and with partial pressures of reactants near the thermodynamic equilibrium. This epitaxial growth of AlN was also related to smooth surface morphology and exhibits hexagonal based hillocks related to a spiral growth around screw dislocations on axis $6 \mathrm{H} \mathrm{SiC}$. With increasing $\mathrm{Cl}_{2}$ flow rate, AlN growth rate increases linearly and the epitaxial layer becomes polycrystalline with increasing deposition rate. The maximum growth rate of polycrystalline layers obtained at high temperature was about $200 \mu \mathrm{m} \mathrm{h}^{-1}$. To conclude, HTCVD seems to be very promising for the development of a further bulk growth process to produce AIN single crystal substrates.

\section{Acknowledgments}

The authors wish to thank $\mathrm{H}$. Roussel for X-ray diffraction experiments, G. Berthome for AFM characterizations and D. De Barros for help in CVD instrumentation.

This work was supported by Acerde, the French Ministère de l'Enseignement Supérieur et de la Recherche and Ministère de l'Economie, des Finances et de l'Industrie.

\section{References}

[1] G.A. Slack, T.F. Mc Nelly, Journal of Crystal Growth 34 (1976) 263.

[2] G.A. Slack, T.F. Mc Nelly, Journal of Crystal Growth 42 (1977) 560

[3] G.A. Cox, D.O. Cummins, K. Kawabe, R.H. Tredgold, Journal of Physical Chemistry of Solids 28 (1967) 543.

[4] T. Renner, Zeitschrift vur Anorganische und Allgemeine Chemie 298 (300) (1959) 22 .

[5] T.L. Chu, D.W. Ing, A.J. Noreika, Solid-State Electronics 10 (1967) 1023.

[6] A.J. Noreika, D.W. Ing, Journal of Applied Physics 39 (12) (1968) 5578.

[7] D.W. Lewis, Journal of the Electrochemical Society 117 (7) (1970) 978.

[8] T.L. Chu, R.W. Kelm Jr., Journal of Electrochemical Society 122 (1975) 995.

[9] J. Bauer, L. Biste, D. Bolze, Physica Status Solidi (A) 39 (1977) 173.

[10] W.M. Yim, E.J. Stofko, P.J. Zanzucchi, J.I. Pankove, M. Ettenberg, S.L. Gilbert, Journal of Applied Physics 44 (1) (1973) 292

[11] M.P. Callaghan, E. Patterson, B.P. Richards, C.A. Wallace, Journal of Crystal Growth 22 (1974) 85.
[12] F. Bugge, A.F. Efimov, I.G. Pichugin, A.M. Tsaregorodtsev, M.A. Chernov, Crystal Research Technology 22 (1) (1987) 65.

[13] A. Nikolaev, I. Nikitina, A. Zubrilov, M. Mynbaeva, Y. Melnik, V. Dmitriev, Materials Research Society Symposium Proceedings (GaN and Related Alloys-1999), 2000, pp.595-598.

[14] V. Williams, E. Pernot, E. Ramberg, E. Blanquet, J.M. Bluet, R. Madar, Material Science Forum: Silicon Carbide and Related Materials 1999 (Part II) 338-342 (2000) 1507.

[15] Y. Melnik, D. Tsvetkov, A. Pechnikov, I. Nikitina, N. Kuznetsov, V. Dmitriev, Physica Status Solidi (A) 188 (1) (2001) 463.

[16] O.Y. Ledyaev, A.E. Cherenkov, A.E. Nikolaev, I.P. Nikitina, N.I. Kuznetsov, M.S Dunaevski, A.N. Titkov, V.A. Dmitriev, Physica Status Solidi (C) 0 (1) (2002) 474.

[17] Y. Kumagai, H. Shikauchi, J. Kikuchi, T. Yamane, Y. Kangawa, A. Koukitu, in: Proceedings of 21st Century COE Joint Workshop on Bulk Nitrides IPAP Conferences Series, vol. 4, 2003, p.9.

[18] Y. Kumagai, T. Yamane, T. Miyaji, H. Murakami, Y. Kangawa, A. Koukitu, Physica Status Solidi (C) 7 (2003) 2498

[19] Y. Melnik, Y. Soukhoveev, V. Ivantsov, V. Sivov, A. Pechnikov, K. Tsvetkov, O. Kovalenkov, V. Dmitriev, A. Nikolaev, N. Kuznetsov, E. Silveira, J. Freitas Jr, Physica Status Solidi (A) 200 (1) (2003) 22.

[20] Y. Kumagai, T. Yamane, A. Koukitu, Journal of Crystal Growth 281 (2005) 62.

[21] T. Yamane, H. Murakami, Y. Kangawa, Y. Kumagai, A. Koukitu, Physica Status Solidi (C) 7 (2005) 2062.

[22] O. Kovalenkov, V. Soukhoveev, V. Ivantsov, A. Usikov, V. Dmitriev, Journal of Crystal Growth 281 (2005) 87.

[23] Y.H. Liu, T. Tanabe, H. Miyake, K. Hiramatsu, T. Shibata, M. Tanaka, Y. Masa, Japanese Journal of Applied Physics (Letters) 44 (17) (2005) L505.

[24] Y. Kumagai, K. Takemoto, J. Kikuchi, T. Hasegawa, H. Murakami, A. Koukitu, Physica Status Solidi (B) 243 (7) (2006) 1431.

[25] V. Soukhoveev, O. Kovalenkov, V. Ivantsov, A. Syrkin, A. Usikov V. Maslennikov, V. Dmitriev, Physica Status Solidi (C) 3 (6) (2006) 1653.

[26] V. Sukhoveev, A. Usikov, O. Kovalenkov, V. Ivantsov, A. Syrkin, V. Dmitriev, C. Collins, M. Wraback, Materials Research Society Symposium Proceedings 892 (29) (2006) 03.1.

[27] Y.-H. Liu, T. Tanabe, H. Miyake, K. Hiramatsu, T. Shibata, M. Tanaka, Journal of Physics: Condensed Matter 16 (2006) 1639.

[28] R.B. Jain, Y. Gao, J. Zhang, R.S. Qhaleed Fareed, R. Gaska, J. Li, A. Arjunan, E. Kuokstis, J. Yang, M. Asif Khan, Physica Status Solidi (C) 3 (6) (2006) 1491.

[29] T. Nagashima, M. Harada, H. Yanagi, Y. Kumagai, A. Koukitu, K. Takada, Journal of Crystal Growth 300 (2007) 42.

[30] K. Tsujisawa, S. Kishino, Y.H. Liu, M. Miyake, K. Hiramatsu, T. Shibata, M. Yanaka, Physica Status Solidi (C) 4 (7) (2007) 2252

[31] T. Nagashima, M. Harada, H. Yanagi, H. Fukuyama, Y. Kumagai, A. Koukitu, K. Takada, Journal of Crystal Growth 305 (2007) 355.

[32] J. Tajima, Y. Kubota, R. Togashi, H. Murakami, Y. Kumagai, A. Koukitu, Physica Status Solidi (C) 5 (6) (2008) 1515.

[33] K.I. Eriguchi, T. Hiratsuka, H. Murakami, Y. Kumagai, A. Koukitu, Journal of Crystal Growth 310 (2008) 4016

[34] Y. Kumagai, J. Tajima, M. Ishizuki, T. Nagashima, H. Murakami, K. Takada, A. Koukitu, Applied Physics Express 1 (2008) 045003.

[35] A. Claudel, E. Blanquet, D. Chaussende, M. Audier, D. Pique, M. Pons, Material Science Forum: Silicon Carbide and Related Materials 2007 600-603 (2009) 1269.

[36] M.T. Duffy, C.C. Wang, G.D. O’Clock Jr., S.H. McFarlane III, P.J. Zanzucchi, Journal of Electronic Materials 2 (2) (1972) 359.

[37] M. Morita, N. Uesugi, S. Isogal, K. Tsubouchi, N. Mikoshiba, Japanese Journal of Applied Physics 20 (1) (1981) 17.

[38] C. Bernard, E. Blanquet, M. Pons, Surface and Coating Technology 202 (4-7) (2007) 790.

[39] SGTE, Institut National Polytechnique de Grenoble (LTPCM), Grenoble, France, 〈http://www.sgte.org

[40] FactSage, 〈http://www.factsage.com〉.

[41] I.N. Przhevalskii, S.Y. Karpov, Y.N. Makarov, MRS Internet Journal of Nitride Semiconductor Research 3 (1998) 30.

[42] K.G. Nickel, R. Riedel, G. Petzow, Journal of American Ceramic Society 72 (10) (1989) 1804.

[43] H. Arnold, L. Bister, T. Kaufmann, Kristall und Technik 13 (8) (1978) 929

[44] A.Y. Timoshkin, H.F. Bettinger, H.F. Schaefer, Journal of the American Chemical Society 119 (1997) 5668.

[45] A. Dollet, Y. Casaux, R. Rodriguez-Clemente, Proceedings-Electrochemical Society (Chemical Vapor Deposition) 97 (25) (1997) 286

[46] W.Y. Lee, W.J. Lackey, P.K. Agrawal, Journal of the American Ceramic Society 74 (1991) 1821

[47] A. Dollet, Y. Casaux, M. Mtecki, R. Rodriguez-Clemente, Thin Solid Films 406 (2002) 1 .

[48] A. Dollet, Y. Casaux, M. Mtecki, R. Rodriguez-Clemente, Thin Solid Films 406 (2002) 118

[49] D. Cai, L.L. Zheng, H. Zhang, V.L. Tassev, D.F. Bliss, Journal of Crystal Growth 276 (2005) 182

[50] M.D. Allendorf, T.H. Osterheld, Proceedings-Electrochemical Society PV 96 (5) (1996) 16

[51] A.H. Mc Daniel, M.D. Allendorf, Journal of Physical Chemistry A 102 (40) (1998) 7804.

[52] W.A. Bryant, Journal of Materials Science 12 (1977) 1285. 
[53] G. Chichignoud, M. Ucar-Morais, P. Pons, E. Blanquet, Surface and Coating Technology 201 (22-23) (2007) 8888

[54] E. Blanquet, C. Vahlas, R. Madar, J. Palleau, J. Torres, C. Bernard, Thin Solid Films 177 (1989) 189.

[55] M. Heyrman, G. Berthomé, A. Pisch, C. Chatillon, Journal of the Electrochemical Society 153 (10) (2006) J107.

[56] K.J. Sladek, Journal of the Electrochemical Society 118 (4) (1971) 654.

[57] M. Suzuki, H. Tanji, Proceedings-Electrochemical Society (Proceedings of International Conference on Chemcial Vapor Deposition, 10th) vol. 87 (8) (1987) 1089.

[58] T. Goto, J. Tsuneyoshi, K. Kaya, T. Hirai, Journal of Materials Science 27 (1992) 247.

[59] M.D. Allendorf, C.F. Melius, The Journal of Physical Chemistry 97 (3) (1993) 720.
[60] P. Rocabois, C. Chatillon, C. Bernard, High Temperatures-High Pressures 27/ 28 (1) (1996) 3.

[61] P. Rocabois, C. Chatillon, C. Bernard, F. Genet, High Temperatures-High Pressures 27/28 (1) (1996) 25.

[62] H. Mank, B. Amstatt, D. Turover, E. Bellet-Amalric, B. Daudin, V. Ivantsov, V. Dmitriev, V. Maslennikov, Physica Status Solidi (C) 3 (6) (2006) 1448.

[63] E. Bellet-Amalric, C. Adelmann, E. Sarigiannidou, J.L. Rouviere, G. Feuillet, E. Monroy, B. Daudin, Journal of Applied Physics 95 (2004) 1127.

[64] K. Chourou, M. Anikin, J.M. Bluet, J.M. Dedulle, R. Madar, M. Pons, E. Blanquet, C. Bernard, P. Grosse, C. Faure, G. Basset, Y. Grange, Materials Science and Engineering B 61-62 (1999) 82.

[65] R. Madar, M. Anikin, K. Chourou, M. Labeau, M. Pons, E. Blanquet, J.M. Dedulle, C. Bernard, S. Milita, J. Baruchel, Diamond and Related Materials 6 (1997) 1249. 